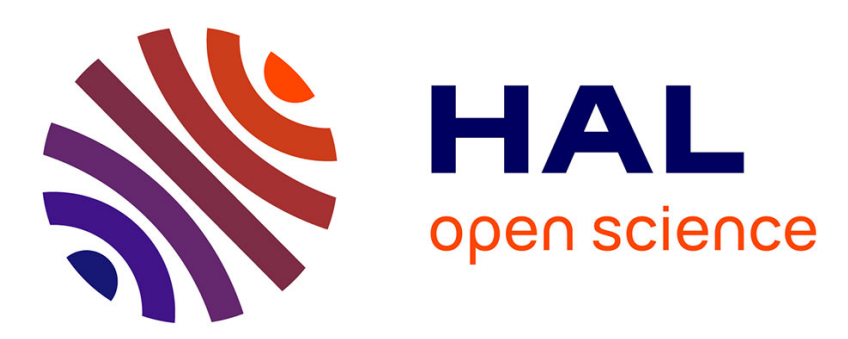

\title{
The Supply Chain Design of Biomass Energy Plants: A Simulation Approach
}

Lorenzo Tiacci, Chiara Paltriccia, Stefano Saetta, Eduardo Martín García

\section{To cite this version:}

Lorenzo Tiacci, Chiara Paltriccia, Stefano Saetta, Eduardo Martín García. The Supply Chain Design of Biomass Energy Plants: A Simulation Approach. IFIP International Conference on Advances in Production Management Systems (APMS), Sep 2014, Ajaccio, France. pp.563-570, 10.1007/978-3662-44733-8_70. hal-01387324

\section{HAL Id: hal-01387324 \\ https://hal.inria.fr/hal-01387324}

Submitted on 25 Oct 2016

HAL is a multi-disciplinary open access archive for the deposit and dissemination of scientific research documents, whether they are published or not. The documents may come from teaching and research institutions in France or abroad, or from public or private research centers.
L'archive ouverte pluridisciplinaire HAL, est destinée au dépôt et à la diffusion de documents scientifiques de niveau recherche, publiés ou non, émanant des établissements d'enseignement et de recherche français ou étrangers, des laboratoires publics ou privés.

\section{(c)(1)}

Distributed under a Creative Commons Attribution| 4.0 International License 
APMS 2014 International Conference,

IFIP Advances in Production Management Systems, Springer

\title{
The Supply Chain Design of Biomass Energy Plants: a Simulation Approach
}

\author{
Lorenzo Tiacci ${ }^{\mathrm{a}}$, Chiara Paltriccia ${ }^{\mathrm{a}}$, Stefano Saetta ${ }^{\mathrm{a}}$, Eduardo Martín García \\ a Università degli Studi di Perugia - Dipartimento di Ingegneria, Perugia, Italia

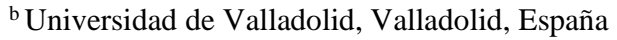

\begin{abstract}
Alternative energies nowadays have to be more competitive than energy derived from fossil fuels. In this study, the supply chain design problem for a biomass plant is considered. In order to reduce the cost per kWh of energy produced, the whole supply chain involving the biomass plant is modeled. A two-steps methodology, consisting in two sequential simulation experiments, is illustrated. The procedure allows to calculate the minimum total surface necessary for wheat production, and to find the size and the number of farms, which minimize the cost per kWh produced, varying different power rating of the plant. Given the general assumptions made, results can be utilized as a decision support tool for the supply chain design of biomass energy plants.
\end{abstract}

\section{Introduction}

The need to be more independent from fossil fuels is leading Europe to an increasing use of alternative energy sources. Among them, biomass is still little considered. In particular, in the Mediterranean area, despite it is a mainly agricultural area due to the mild climate, the numerous waste resulting from cereal production could be utilized for energy production from biomass.

In this paper, a support decision tool for the design of the supply chain of a biomass plant is proposed. This study is conducted through a simulation approach, which allows finding the best configuration for a network of farms that supply a biomass energy production plant placed in a central position. In fact, due to the high number of variables that have to be considered, the stochastic nature failures rate of machines and the limited capacity of storages, blockings and starvations phenomena arise along the nodes of the supply chain. For this reason it is very difficult to study the supply chain through analytical models.

The procedure proposed in this paper consists into two sequential steps. In the first one, the aim is to determine the necessary field extension related to different power rating of the plant. In the second step, the goal is to evaluate the optimal number and size of farms required to handle efficiently the resources in order to minimize the cost per kWh produced.

The paper is organized as follows: the next section provides a brief review of the literature on the design of the supply chain in the production of energy from biomass. 
In Section 3 and 4 the conceptual and the simulation model are respectively described. In Section 5 the design of experiment is illustrated. Results are discussed in Section 7 and in Section 8 a brief summary is drawn.

\section{Literature Review}

Alternative energy and Supply Chain (SC) have a central role in social and economic development at different stages [1]. As outlined in [2], the supply chain capacity is among the main issues for alternative energy development, together with project economics, technical constraints, social effects and environmental impacts .

The management of a biomass plants requires timely supply of feedstock with minimum logistics costs and an optimized biomass logistics system [3]. Several methods have been used to model and analyze different aspects of agricultural biomass supply chains. In [4] a location model for a biomass plant, based on an AHP approach, is proposed. Different type and issues on biomass supply chains were studied through static spreadsheet models in order to calculate the costs related to storage and transportations [5-7]. Indeed, as a further study, mathematical optimization-modelling tools were proposed as another methodology to optimize logistical decisions [8-10].

These static models are not able to describe the dynamic behavior and the complexity related to a biomass supply chain, that can be achieved only adopting simulation approaches [11]. Simulation approaches have been also utilized to validate analytical models developed for multi-echelon supply chains of bulk materials such as grain [12]. Among the simulation frameworks, the Integrated Biomass Supply Analysis and Logistics (IBSAL) model [11] considers various stages of the agricultural biomass logistics system. This model has been further enhanced considering the demand fulfilment and in-farm and at-plant storage management, considered in the IBSAL Multi Crop (IBSALMC) model [13].

In our work we developed a conceptual model inspired by IBSALMC, and a corresponding simulation model implemented in Arena. These models have been utilized to propose a design methodology and a decision support tool for the supply chain design of biomass plants.

\section{Conceptual Model}

A biomass plant, which produces energy from wheat biomass, is considered in this work. To provide this plant whit a sufficient quantity of wheat biomass it is necessary a specific area around the plant in which a certain number of farms is distributed. Each farm manages a different field surface cultivated with one cereal farming. Farms are allocated on an approximately circular area (Fig. 1).

Wheat is harvested during the summer. After harvesting, wheat is left on the field for a certain period, in order to dry. When the yield is ready, it is baled by a square baler, a machine used to compact yield into square bales of $1.2 \mathrm{~m} \mathrm{x} 1.2 \mathrm{~m} \mathrm{x} 2.4 \mathrm{~m}$ and $500 \mathrm{~kg}$ of weight each. 


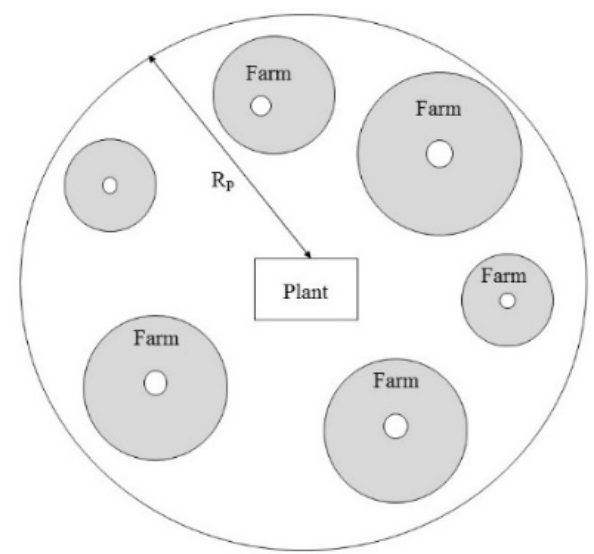

Fig. 1. Schematic representation of the plant and the network of farms

Bales are then left onto the field until a stinger stacker, a machine that picks up 8 bales per trip, collects and stores them into a farm Roadside Storage (RS). The operating turn of a stinger stacker begins at 6:00 a.m. and ends at 20:30 p.m., considering a break time for lunch at 12:30 p.m. Each farm owns a RS of a fixed capacity of 800 bales. The bailing collecting process is interrupted if the RS is full.

During the processes involved in the supply chain, while the bales stay in the field waiting to be stored, they lose weight due to the natural drying process. This mass loss causes a reduction of the total energy that can be produced by the plant.

The biomass plant owns a truck that collects bales from each farm to feed its grinder. When in the farm storage there are enough bales to fulfil a truck (at least 8 bales), the truck is called from the biomass plant, bales are loaded onto the truck by a tele-handler and then the truck drives bales to the plant, where they are stocked and then used to feed the grinder and to produce biomass energy. Farms that claim for the truck simultaneously are served following a FIFO policy. It is important to highlight that in this RS a sufficient number of bales should always be present in order to ensure a continuous feeding of the plant grinder.

The annual costs considered are divided into two main categories: logistics and storage costs. In detail, costs considered are: cost per hour of each machine, cost of failures, cost of transportations, and holding costs.

The processes that forerun the storing of bales at the plant are very important, because they are responsible of the continuous production of the plant. Blocking and starvation phenomena along the nodes of the described SC arise due to the following reasons:

1. Limited capacity of resources (balers, stingers stacker, tele-handlers, truck, RS, plant storage, grinder)

2. Stochastic failures of machines (balers, stingers stacker, tele-handlers, truck, grinder). 
Due to space limitation it is not possible to report in detail all the features characterizing the model, which will appear in an extended version of the paper.

\section{$4 \quad$ Simulation Model}

The simulation model, built using Arena by Rockwell Software, is an indexed model. This feature of Arena is very useful when repetitive components are modelled, as the farms in our conceptual model. Through an 'ID', which is an integer number within a specific class, each object can be viewed as an object arrays. The index identifies the object in the array. In this way, resources, queues, expressions, processes can be represented by vectors or matrices [14]. An indexed model is a parametric model, and this is fundamental to perform scenario analysis, because it allows avoiding to reprogram the model varying the number of farms.

The hypotheses considered in the model are: times related to each process are deterministic; times related to failures of machines are stochastic and exponentially distributed. We validated our model through two widely adopted techniques [15]. The first one consists in computing exactly, when it is possible and for some measures of the input parameters, some measures of outputs, and using it for comparison. The second one, an extension of the first one, is to run the model under simplifying assumptions for which is the true characteristics are known and, again, can easily be computed.

The processes involved in the SC are modelled as seven blocks (Fig. 2).

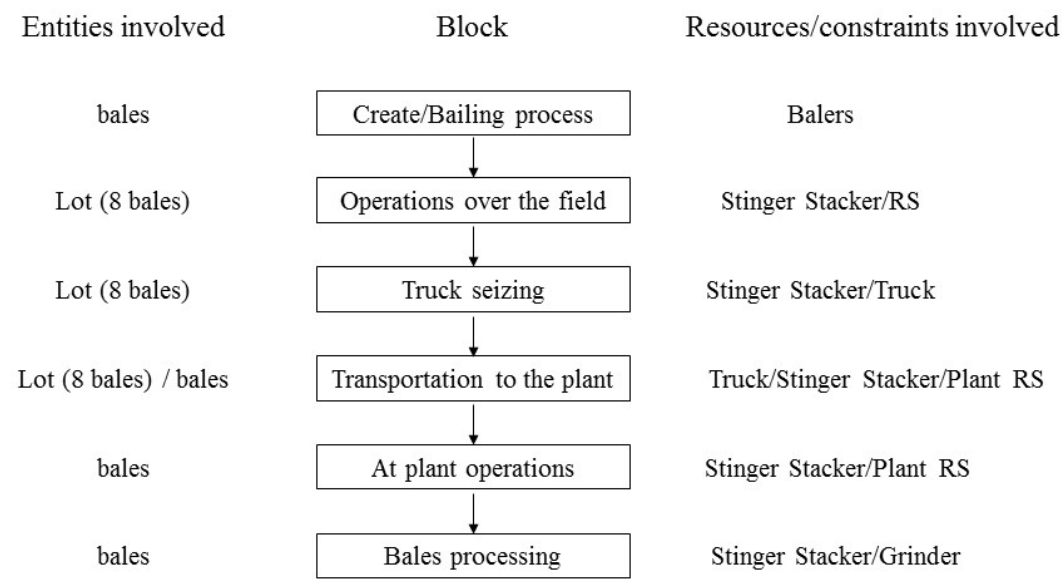

Fig. 2: Diagram representation of the main blocks of the simulation model

The simulation starts with the harvest. The first block is the creation of bales, which corresponds to the bailing process. Bales are created in according to the bailer capacity. The second block is related to the operations over the field, where the stinger stacker collects bales and forms lots, each containing 8 bales, that become the basic 
entities. When the number of lot waiting in the RS is reached, the truck is claimed. Truck availability depends on the state of the processes of the other farms. The third block represents the process related to the truck seizing and the bales loading. This process involves the stinger stacker and the plant truck and it is followed by the transportation to the plant and the bales unloading process, which involves the plant truck and the stinger stacker. The last two blocks are related to the at-plant operations, in particular to the storage and to the bales processing. Details related to resources involved and entities considered are described in Fig. 2.

The model is completed with three independent sub-models, which make use of dummy entities. The first one is realized for indexing motivations, and is related to the assignment of specific attributes to each farm (f.e. size of the farm, distance from the plant, etc.) varying the number of farms generated. The second and the third submodels are essentially built to record statistics in specific moments of the simulation.

\section{$5 \quad$ Design of Experiment and Results}

In order to explain a methodology to design the optimal configuration of the supply chain that provides wheat to a biomass plant for energy production, two different experiments were built. The first experiment is aimed at evaluating which is the optimal extension of the total surface involved in the wheat production for a biomass plant of a given power rating. The second experiment is performed to evaluate the optimal number of farms, and therefore their optimal size, in order to reduce the unitary cost of energy produced. Each experiment is conducted for four different power rating of the plant: $200 \mathrm{~kW}, 400 \mathrm{~kW}, 600 \mathrm{~kW}$ and $800 \mathrm{~kW}$, and has been replicated ten times. All the results refer to the average values obtained from the simulations.

\subsection{Experiment 1}

As before mentioned, the aim is to determine the extension of the total surface needed in the wheat production for a biomass plant, given the power rating of the plant. A specific area shall be managed by a high number of little farm or by a low number of big farms. To calculate the total surface for each power rating of the plant, a scenarios analysis have been performed. In each scenario the number of farms $N_{F}$ varies in an interval of [10, 70], with $N_{F}$ multiple of 5 . The size of each farm has been generated randomly from a uniform distribution with a range $[10,30]$ ha.

The minimum number of farms which guarantees at least the $90 \%$ of utilization rate of the plant is considered for calculating the total surface required. By multiplying the number of farms $N_{F}$ and their average extension, it has been possible to calculate the total surface required by the plant. This procedure has been replicated for different power rating of the plant.

In Table 1 the results are reported for each scenario. The total surface found are: 300 ha for a $200 \mathrm{~kW}$ power plant, 600 ha for a $400 \mathrm{~kW}$ power plant, 900 ha for a $600 \mathrm{~kW}$ power plant and 1200 ha for a $800 \mathrm{~kW}$ power plant. 


\begin{tabular}{cccccc}
\hline Farms & $\begin{array}{c}\text { Total surface } \\
\text { [ha] }\end{array}$ & $200 \mathrm{~kW}$ & $400 \mathrm{~kW}$ & $600 \mathrm{~kW}$ & $800 \mathrm{~kW}$ \\
\hline 10 & 200 & 68.11 & - & - & - \\
15 & 300 & $\mathbf{9 5 . 1 7}$ & - & - & - \\
20 & 400 & 99.72 & - & - & - \\
25 & 500 & 99.83 & 81.04 & - & - \\
30 & 600 & 99.86 & $\mathbf{9 3 . 5 8}$ & - & - \\
35 & 700 & - & 99.63 & - & - \\
40 & 800 & - & 99.33 & 84.49 & - \\
45 & 900 & - & 99.89 & $\mathbf{9 2 . 9 7}$ & - \\
50 & 1000 & - & - & 98.73 & 79.47 \\
55 & 1100 & - & - & 99.90 & 86.21 \\
60 & 1200 & - & - & 99.93 & $\mathbf{9 2 . 4 6}$ \\
65 & 1300 & - & - & - & 97.64 \\
70 & 1400 & - & - & - & 99.85 \\
\hline
\end{tabular}

Table 1. Results of Experiment 1

\subsection{Experiment 2}

Experiment 2 represents the second stage of the design methodology. Aim of this second stage is to evaluate the optimal number of farms, and therefore their size, in order to reduce the unitary cost of energy produced. Indeed the same surface can be managed or by a great number of small farms or by a small number of large farms (Fig. 3). The total surface necessary to guarantee a sufficient supply of wheat to the plant represents the fundamental input data.

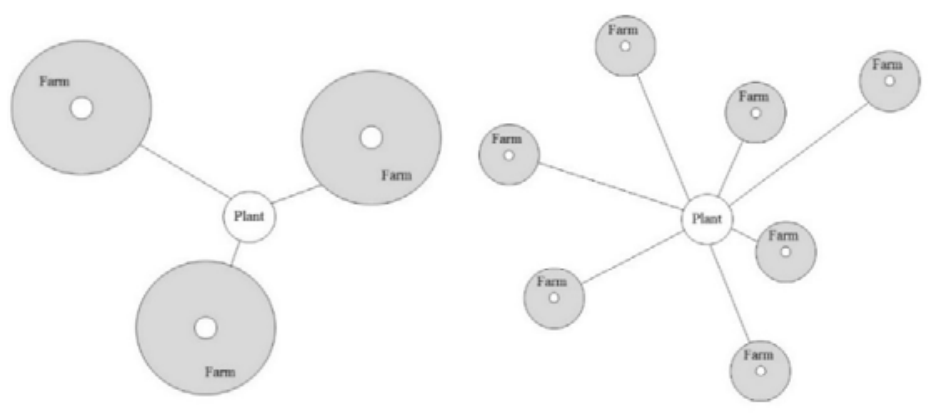

Fig. 3. Schematic representation about two possible opposite configuration of the network

The scenario analysis performed for each power rating is developed in the following way. A certain number of scenario are generated varying the number of farms $N_{F}$ from 10 to 70 . For each scenario, the average surface $m_{k}$ of each farm is calculated as the ratio between the total surface required by the plant and the number of farms con- 
sidered. Then the surface of each farm is randomly generated from a uniform distribution with range $\left[m_{k}-5, m_{k}+5\right]$ ha.

The optimal combination of number/size of the farms, which allows to minimize the cost per kWh of energy produced, is the one in which the appropriate number of machines and resources operates with reduced queues and idle times. In fact, it is not only necessary to own a sufficient area ensuring a sufficient total quantity of wheat, but is also important to ensure a continuous flow of material from the farms to the plant. Results related to Experiment 2 are reported in Fig. 4. It is possible to highlight that the functions that describe the costs per kWh, varying the number of farms, are always convex. The optimal number of farms, as expected, increases as the power of the system increase.

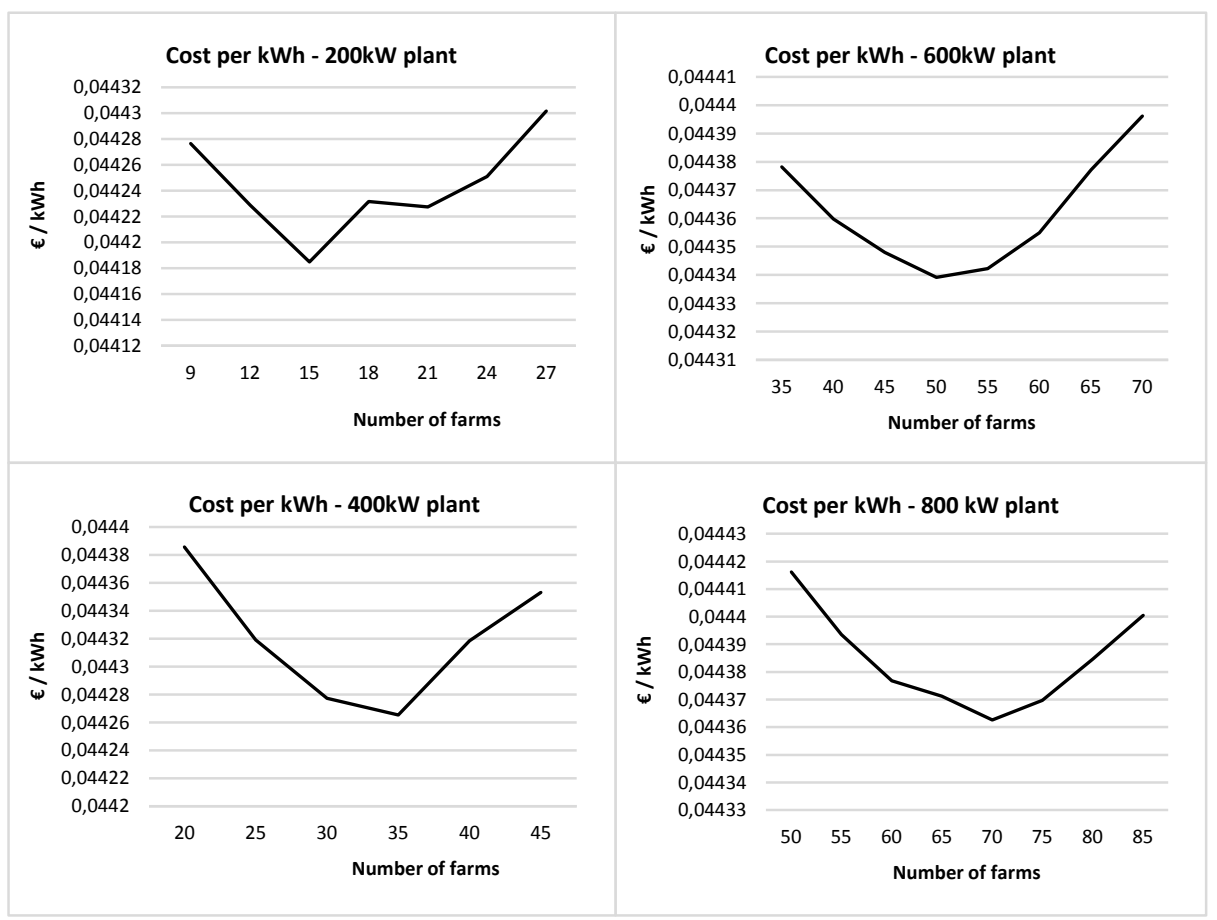

Fig. 4. Cost per kWh as a function of the number of farms

\section{Summary}

This research study analyzed the SC of a biomass plant evaluating costs for different power rating of the plant. This study was conducted adopting a simulation approach. The results achieved are valid under the assumptions made in the conceptual model. These assumptions are applicable to a large set of wet biomass supply chains. Thus, the relations found among the power rating of the plant and the optimal number and size of farms can be utilized as a supporting decision tool for the preliminary design of this type of supply chains. This model can be further developed considering other 
realistic aspects, such as weather conditions, the rotting process of the bales, and different variety of crops. Even other resource management policies could be considered, such as the sharing of resources like balers and stinger stackers among farmers.

\section{$7 \quad$ References}

1. Shi, V.G., Koh, S.C.L., Baldwin, J., Cucchiella, F.: Natural resource based green supply chain management. Supply Chain Manag 17, 54-67 (2012)

2. Cucchiella, F., D'Adamo, I.: Issue on supply chain of renewable energy. Energ Convers Manage 76, 774-780 (2013)

3. Sokhansanj, S., Kumar, A., Turhollow, A.F.: Development and implementation of integrated biomass supply analysis and logistics model (IBSAL). Biomass Bioenerg 30, 838847 (2006)

4. De Carlo, F., Schiraldi, M.: Sustainable choice of the location of a biomass plant: an application in Tuscany. International Journal of Engineering and Technology 5, (2013)

5. Allen, J., Browne, M., Hunter, A., Boyd, J., Palmer, H.: Logistics management and costs of biomass fuel supply. Int J Phys Distr Log 28, $463-477$ (1998)

6. Brundin, S.: Fuels from agriculture. Cost calculations of systems based on straw and energy grass. Department of Economics, Swedish University of Agricultural Sciences. (1988)

7. Clegg, J.M., Noble, D.H.: A cost model of straw conservation systems. Agricultural Engineering (1987)

8. Eksioglu, S.D., Acharya, A., Leightley, L.E., Arora, S.: Analyzing the design and management of biomass-to-biorefinery supply chain. Comput Ind Eng 57, 1342-1352 (2009)

9. Rentizelas, A.A., Tatsiopoulos, I.P., Tolis, A.: An optimization model for multi-biomass tri-generation energy supply. Biomass Bioenerg 33, 223-233 (2009)

10. Rentizelas, A.A., Tolis, A.J., Tatsiopoulos, I.P.: Logistics issues of biomass: The storage problem and the multi-biomass supply chain. Renew Sust Energ Rev 13, 887-894 (2009)

11. Ebadian, M., Sowlati, T., Sokhansanj, S., Stumborg, M., Townley-Smith, L.: A new simulation model for multi-agricultural biomass logistics system in bioenergy production. Biosyst Eng 110, 280-290 (2011)

12. Saetta, S., Paolini, L., Tiacci, L., Altiok, T.: A decomposition approach for the performance analysis of a serial multi-echelon supply chain. Int J Prod Res 50, 2380-2395 (2012)

13. Ebadian, M., Sowlati, T., Sokhansanj, S., Townley-Smith, L., Stumborg, M.: Modeling and analysing storage systems in agricultural biomass supply chain for cellulosic ethanol production. Appl Energ 102, 840-849 (2013)

14. Altiok, T., Melamed, B.: Simulation modelin and analysis with Arena. Elsevier, USA (2007)

15. Law, A.M., Kelton, W.D.: Simulation Modeling and Analisys (2000) 